\title{
The effects of excise taxes and regulations on cigarette smoking*
}

\author{
Jeffrey Wasserman** \\ Health Policy Research Division, SysteMetrics McGraw-Hill, Santa Barbara, CA 93101, USA
}

Willard G. Manning

School of Public Health. University of Michigan, Ann Arbor, MI, USA

\author{
Joseph P. Newhouse \\ Division of Health Palicy Research and Eduration. Horvard Liniversity, Cambridge. MA. USA
}

John D. Winkler

Behavioral Sciences Department, The RAND Corporation, Santa Monica, CA, USA

Received January 1990, final version received November 1990

\begin{abstract}
We estimate a generalized linear model to examine adult and teenage cigarette demand. Our analysis focuses on the extent to which excise taxes and regulations restricting smoking in public places affect cigarette consumption. The adult results indicate that the price elasticity of demand is unstable over time, ranging from 0.06 in 1970 to -0.23 in 1985 . These estimates are lower than most found in previous studies. The teenage price elasticity does not differ statistically from the estimates for adults. Additionally, regulations restricting smoking in public places have a significant effect on both adult and teenage cigarette demand.
\end{abstract}

\section{Introduction}

The results from over three decades of research on the health consequences of cigarette smoking have been astonishing, leading a former Surgeon General of the United States to conclude that smoking is the chief, single

\footnotetext{
* Research for this paper was supported, in part, by the Pew Charitable Trusts. The authors wish to thank Michael Grossman and two anonymous referees for their helpful comments on an earlier version of the paper, Robert Bell for developing the software used to estimate the generalized linear model, Alicia Bell for her data management support, and Marlise Goodwin for her assistance in preparing the manuscript.

**Address all correspondence to: Jeffrey Wasserman. SysteMetrics/McGraw-Hill. 104 West Anapamu Street, Santa Barbara, CA 93101, USA.
} 
avoidable cause of death in our society and the most important public health issue of our time' [U.S. Department of Health and Human Services (1982)]. Cigarettes are blamed for over 390,000 premature deaths annually, which represent a combined loss of approximately four million years of life [U.S. Department of Health and Human Services (1989), Centers for Disease Control (1987)]. ${ }^{1}$

The toll taken by cigarette smoking has stimulated the development and implementation of a number of policies to control smoking. This paper examines two such policies: excise taxes and regulations restricting cigarette smoking in public places.

Although cigarettes have been taxed by the federal government for over 100 years and by all states for over 20 years, regulations limiting smoking in public places were relatively rare prior to 1970 . However, the growth of these regulations during the 1970 s was impressive. As of 1970 , only 14 states had laws in place that limited smoking. By 1986, 41 states and the District of Columbia had enacted laws governing smoking in public places [U.S. Department of Health and Human Services (1986a)].

Although many states have laws that restrict smoking, the laws are not of equivalent stringency. In fact, the restrictiveness of the statutes varies considerably across states. For example, South Carolina restricts smoking on school buses only, while Florida, Minnesota, Nebraska, and Washington each restrict smoking in 15 types of public places, including both public and private worksites.

With the exception of the recent smoking ban on domestic airplane flights, no federal legislation has been passed that restricts smoking in public places (although regulations have been enacted to restrict smoking in some federal buildings), and local initiatives of any consequence did not materialize until the early- to mid-1980s. As a result, the regulations that this paper examines are exclusively at the state level.

\section{Selected cigarette demand studies}

Estimates of the price elasticity of demand for cigarettes vary considerably. For example, Lewit and Coate (1982), in their review of United States studies completed since 1970 , reported estimates that range from -0.40 to -1.30 . Estimates of the income elasticity of demand indicate that cigarettes are apparently income inelastic, with the estimates ranging from 0.08 to 0.93 .

The broad range in price and income elasticity estimates appears to be attributable to differences in both data and estimation techniques. Many

\footnotetext{
${ }^{1}$ Calculated using an average life expectancy of 75 years.
} 
studies used aggregate time-series data to estimate demand models, with the unit of anaiysis being either the nation or the state. For example, Baltagi and Levin (1986) pooled cross-sectional and time-series data from 46 states between 1963 and 1980 to estimate their cigarette demand model. Their results showed an own price elasticity of -0.22 and a neighboring state price elasticity of 0.08 . Fujii (1980) used time-series data and ridge regression techniques and found price and income elasticities of -0.47 and 0.22 , respectively. Warner (1981) used aggregate time-series data from 1947 to 1978 to obtain an estimated price elasticity of demand of -0.37 .

Only a handful of studies have used micro data to estimate cigarette demand models. Using data from the Health Examination Survey, Lewit et al. (1981) examined two measures of teenage smoking behavior: whether the teenager smoked and, if so, the quantity smoked per day. The estimated elasticities for both the smoking participation equation and the quantity smoked equation were large (i.e., -1.19 and -1.44 ) in relation to those found in other studies.

Using data from the 1976 Health Interview Survey, Lewit and Coate (1982) estimated price and income elasticities of adult cigarette demand. The authors offer a cogent argument to support their view that using data on individuals is preferable to that of using states as the units of observation because the latter approach produces elasticity estimates that are biased away from zero. This bias results from the fact that sales figures based on taxes paid fail to adequately reflect actual consumption, because there is considerable smuggling or bootlegging of cigarettes from low to high tax states. To eliminate the potential for producing biased estimates, Lewit and Coate's analysis excluded individuals who lived in communities where the price of cigarettes exceeded another price found within a 20 mile wide band around their place of residence. The regression estimates obtained from this 'restricted sample' indicated an overall price elasticity of -0.42 and an income elasticity of 0.08 .

Finally, several recent studies have applied a 'rational addiction' model to cigarette demand. This modeling approach maintains that there are important intertemporal linkages in cigarette consumption that should be accounted for in demand estimation efforts. Becker et al. (1990) used cigarette sales data from 1955 through 1985 to estimate a cigarette demand model based on a rational addiction framework. Their results indicated that a $10 \%$ permanent increase in the price of cigarettes reduced cigarette consumption by $4 \%$ in the short run and $7.5 \%$ in the long run. Using a similar analytic framework, Chaloupka (1990) found that men had a longrun price elasticity of -0.60 , while women were unresponsive to cigarette price changes. Earlier, Mullahy (1985) estimated several cigarette demand models that accounted for past consumption, and found that the price elasticities obtained averaged -0.47 . 


\section{Data and methods}

Most of the data used in our analysis came from the National Health Interview Survey (NHIS). The NHIS is a national survey of the civilian noninstitutionalized population conducted annually by the National Center for Health Statistics (NCHS) [for additional details on the NHIS sample design, see Schoenborn (1987)]. This analysis used data from seven of the nine smoking supplemental questionnaires administered between 1970 to 1985 . During this period, questions relating to smoking behavior were asked in the following nine years: 1970, 1974, 1976, 1977, 1978, 1979, 1980, 1983, and $1985 .^{2}$

In all, data on 207,647 individuals and their smoking habits were collected between 1970 and 1985 (excluding 1977 and 1978). However, due to NCHS confidentiality safeguards, a fraction of these individuals were excluded from the analysis. Specifically, in order to link an individual with an appropriate cigarette price, the individual's location (i.e., primary sampling unit, or PSU) needed to be determined. However, the National Center for Health Statistics recodes the PSUs on the NHIS public use tapes for confidentiality reasons. Thus, to conduct this research, an arrangement was reached with NCHS staff that enabled us to assign cigarette prices to individuals in the data set while preserving the true identities of their PSUs.

We assigned cigarette prices to individual respondents as follows. To begin with, each of three sets of PSUs were located on a map. The first set, which was used in the 1970 survey, contained 413 PSUs; the second, used from 1974 through 1983, contained approximately 425 PSUs (although the number of PSUs used in a given year during this time period varied somewhat from this figure); and the third, used in 1985, had 235 PSUs. Second, using price data from the Tobacco Institute's 1986 report, The Tax Burden on Tobacco, a cigarette price was determined for each PSU. ${ }^{3}$

Next, following Lewit and Coate (1982), 20-mile bands were drawn around each PSU in order to determine whether the residents of the PSU bordered on an area that had lower-priced cigarettes. ${ }^{4}$ If any part of a given PSU

\footnotetext{
${ }^{2}$ Unfortunately, due to difficulties in obtaining the 1977 and 1978 data, these years were excluded from the analysis. However, given that they fall more or less in the middle of the interval being studied, and that the surrounding years (i.e., 1976 and 1979) were included, it is unlikely that their omission resulted in a significant loss, in terms of the precision and stability of the estimates.

${ }^{3}$ We added local taxes in the PSU-specific prices if the PSU was located in, or encompassed, one of the 388 cities, towns, or counties that impose cigarette excise taxes. City and county population data were used to develop weighted average local taxes for the PSUs (which were typically counties) that encompassed a city or town that taxed cigarettes.

${ }^{4}$ The choice of an appropriate band is admittedly somewhat arbitrary. Initially, we used both 10- and 20-mile bands around each PSU so that a sensitivity analysis could be performed to determine how the estimated parameters vary with alternative assumptions regarding the extent of informal bootlegging. However, due to the conditions imposed by NCHS, multiple bands would have required the elimination of an excessive number of PSUs.
} 
was within 20 miles of a lower-priced area, then a 'border' variable for that PSU was assigned a value of one, otherwise the 'border' variable assumed a value of zero. The border variable was later used to account for the possibility of informal bootlegging, a situation in which a potential or confirmed smoker purchases cigarettes in a lower-price area while he or she, for instance, is commuting to work. Approximately $13 \%$ of the PSUs and observations were eliminated from the analysis as a result of a condition imposed by NCHS (to maintain confidentiality) that no PSU could contain a unique price/border variable combination. That is, there had to be at least two PSUs that had the identical price and border variable information.

After the prices and border variables were merged with the NHIS data, we matched data on state regulations governing smoking in public places to the file. States were identified through the price data, as prices vary by state.

\subsection{Underreporting}

There is persuasive evidence that suggests that cigarette consumption from survey data such as the NHIS is underreported because of the social undesirability of smoking. ${ }^{5}$ Warner (1978) showed that reported cigarette consumption in 1975 was only two-thirds of actual consumption (as measured in sales). ${ }^{6}$ Thus, in estimating cigarette demand, one would ideally like to adjust reported consumption to reflect underreporting. However, information on the extent to which underreporting varies with the level of consumption - for instance, whether heavy smokers are more apt to underreport their consumption than light ones - is not available. Consequently, we assumed that all consumption is underreported by approximately one-third. Moreover, because multiplicative models were estimated, only the intercept would be affected by underreporting, so no adjustment was made to reported consumption.

\subsection{Data on teenage smoking behavior}

From both a research and a policy perspective, it is important to address the smoking behavior of teenagers, as most individuals start to smoke during their teenage years [U.S. Department of Health and Human Services (1986b)]. Teenagers' responses to excise tax changes and anti-smoking laws

\footnotetext{
${ }^{5}$ Underreporting is generally assumed to be a problem with respect to the number of cigarettes smoked, not whether one is a smoker. Although there is no direct evidence to support this assumption, a study by Marquis et al. (1981) found that, in the case of alcohol consumption, studies of abstaining versus drinking alcohol revealed that self-reports of abstention were "highly valid'.

${ }^{6}$ More recently, Hatziandreu et al. (1989) examined the reliability of self-reported cigarette consumption between 1974 and 1985 and found that the ratio of reported to (estimated) actual consumption was remarkably stable throughout the period.
} 
may differ from adults because of the progression of addiction. Lewit et al. (1981) found that the price elasticity of demand for teenagers is substantially greater than the corresponding figure for adults.

Unfortunately, the NHIS data do not contain smoking-related information on children under age 17 (or 20, depending on the year the survey was administered). Hence, in order to examine teenage smoking behavior we used a second data set: the National Health and Nutrition Examination Survey II (NHANES II). This data set contains smoking and socioeconomic information that is comparable to that of the NHIS. The period of time covered in NHANES II ranged only between 1976 and 1980, and only 1,960 teenagers were asked smoking-related questions.

\subsection{Price and income data}

Data on cigarette prices came from the Tobacco Institute. The Tobacco Institute publishes yearly state averages of prices weighted by type of sale (i.e., single package sold over-the-counter, carton, and vending machine). The weights used to calculate average price by state are based on national market shares by type of sale. ${ }^{7}$

Data on family income available in both the NHIS and NHANES are categorical. To obtain a point estimate for each category, we used data from the Current Population Survey (CPS), which measures income continuously, and estimated a set of means in the CPS data that correspond to the NHIS and NHANES income categories. We judged the CPS to be a good source of income data because it has a sampling frame similar to that of the NHIS.

All data on cigarette prices and personal incomes were deflated to constant (1967) dollars using the Consumer Price Index for All Urban Consumers (CPI-U).

\subsection{Regulation data}

Data on regulations restricting smoking in public places came from reports published by the U.S. Department of Health and Human Services (1986a, b), which included abstracts of the applicable laws. In some instances, we consulted state statutes because the abstracts were insufficient to determine when a particular statute was enacted. Taken together, these sources provided information on whether and, if so, when a particular state enacted a law that restricted smoking in each of the following places: public buses and trains, elevators, indoor recreational or cultural facilities, retail stores,

${ }^{7}$ The use of these price data could potentially introduce an endogeneity problem if relatively heavy smokers are more likely to purchase their cigarettes by the carton (i.e., the lowest priced method of purchase). Unfortunately, due to data limitations, we are unable to control for method of purchase. 
restaurants, schools, health care facilities (e.g., hospitals and nursing homes), public meeting rooms, libraries, rest rooms, waiting rooms, public worksites, private worksites, and 'other' public places (e.g., jury rooms, halls and stairs, polling places, and prisons). Additionally, we determined whether laws were enacted that restricted the sale or distribution of cigarettes to minors.

We collapsed these data into a regulation index, which was similar to one described in the Surgeon General's 1986 report [U.S. Department of Health and Human Services (1986a)]. The U.S. DHHS index is an updated and modified version of an index developed by Warner (1981). States that regulate smoking in a large number of places and/or places where people spend a large fraction of their time received higher scores than states that only limit smoking in a handful of relatively unimportant places (e.g., elevators). If a state restricted smoking in private worksites, then it received a score of one, because people spend more time at work than any other place outside the home. States that restricted smoking in restaurants, but not in private worksites, received a score of 0.75 . If a state failed to restrict smoking in both private worksites and restaurants but imposed restrictions on smoking in at least four other public places, then it received a score of 0.50 . States that had between one and three of these relatively minor restrictions in place were scored 0.25 , and states with no regulations in place received a score of zero. Specification tests indicated that this scaling was appropriate.

\subsection{Dependent and explanatory variables}

Cigarette consumption was measured in terms of packs per day, with nonsmokers' consumption set at zero. Packs per day equal the reported number of cigarettes smoked per day divided by 20 .

The adult and teenage equations share many of the same explanatory variables. Both equations, for instance, contain price, regulation, age, sex, race, education, family income, family size, and year variables. Past studies have shown that all of these variables influence smoking behavior, with the exception of the regulation index, which has never been used in a multiple regression analysis. ${ }^{8}$

The adult model also included a set of variables defining birth cohorts. Although previous econometric studies of cigarette demand have ignored cohort effects, the prevalence of smoking varies considerably by cohort [Harris (1983)]. Cohort variables could control for an individual's exposure to various cultural aspects of smoling - for example, its increased popularity among men during World War II and the recent advent of a strong antismoking movement that developed in response to the adverse health effects

\footnotetext{
${ }^{8}$ Several authors, however, have used regression techniques to examine the effects of regulations. For example, Chaloupka (1988) included a dummy variable indicating whether a state passed a Clean Indoor Air law in his analysis of smoking demand.
} 
of smoking. These effects cannot be fully captured by including only age and year variables in the model. ${ }^{9}$

\subsection{Statistical analysis}

We estimated a generalized linear model of the type suggested by Nelder and Wedderburn (1973) and McCullagh and Nelder (1983), using an iterative weighted least squares technique. While this estimation approach is similar to ordinary least squares (OLS), it is preferable to OLS for modeling cigarette demand.

OLS was rejected as the primary modeling approach for several reasons. To begin with, a preliminary analysis of the data revealed that, with respect to the number of packs smoked, the mean and the variance were roughly equivalent, which suggested a generalization of the Poisson distribution. Second, as is the case with many demand functions, we expected a multiplicative or proportional relationship rather than an additive one. This was later confirmed empirically through a series of log-scale linearity tests. Third, least squares does not address well the truncation of consumption at zero combined with the skewed consumption.

We found the pseudo-Poisson specification attractive for three reasons. First, it is in many ways analogous to more familiar regression techniques in that $E\left(n_{i t} \mid x_{i t}\right)=\lambda_{i t}$, where $n_{i t}$ is the count of packs smoked at time $t$ and $\lambda$ is the Poisson parameter of the form $\log \lambda=x \beta$, where $x$ is a matrix of $K$ columns, with each column being a vector of $T$ observations on one of $K$ independent variables and $\beta$ is a column vector of $K$ unknown parameters to be estimated. Second, the 'zero problem' (i.e., a substantial fraction of the observations are not current smokers) is a natural outcome of Poisson processes. Hence, the use of this sort of model avoids the problems found in typical logarithmic regression models in which the dependent variable can assume a value of zero. Third, as we will see, the pseudo-Poisson model is relatively easy to interpret.

The model we estimated departs from a true Poisson model because it allowed for fractional packs of cigarettes. This, however, should neither affect the parameter estimates nor the inferences drawn from the model because we estimated the model by iteratively weighted least squares. To avoid confusion, we will refer to the model as the generalized linear model.

To both confirm and decompose the generalized linear model's results, we estimated a two-part model of the demand for cigarettes based on a model developed by Cragg (1971). Once again, separate equations were estimated for adults and teenagers. Using logistic regression analysis, we first estimated

\footnotetext{
${ }^{9}$ Because we included age, cohorts, and year in the model, the age variables are difficult to interpret directly. Essentially, the age variables measure within-cohort aging effects.
} 
a model of an individual's decision to smoke as a function of the same covariates used in the generalized linear model. A dichotomous dependent variable was used to indicate whether an individual was a current smoker.

The second part of the model was estimated using ordinary least squares, and showed the level of demand for current smokers. The same set of covariates used in the smoking decision equation was used to predict the quantity of cigarettes smoked. This equation, then, was conditioned on smoking. The overall demand for cigarettes can be obtained by multiplying the probability equation by the conditional one. ${ }^{10}$

\subsection{Split sample}

To ensure that the models did not 'overfit' the data, we used a split sample approach for model estimation. We conducted exploratory data analyses using a random subsample of 42,412 NHIS cases, roughly $25 \%$ of the available cases. ${ }^{11}$ However, after eliminating cases with missing data, the number of cases that remained in the subsample fell to 34,703 . There did not appear to be any systematic differences between the cases with and without complete data.

After estimating the models, a simple one degree of freedom test - in which the residuals were regressed on the forecasts for all data that were not used to estimate the models - was used to validate the models. After validation, the final models were reestimated using all of the remaining data, which increased the precision of the estimated parameters. Although the basic structures of the models proved sound when they were reestimated using the larger data set, some important interaction effects were detected.

\subsection{Teenage cigarette demand model}

We followed a similar modeling approach for estimating teenage cigarette demand. The major differences between the two models included different data sets (as mentioned earlier) and a somewhat different set of covariates. For example, the teenage model did not include education variables, because the presence of compulsory education through age 16 results in an almost perfect correlation between education and age. ${ }^{12}$ Instead, a set of variables

\footnotetext{
${ }^{10}$ The formula used to calculate the overall price elasticity of demand was $\eta=$ $(1-p)\left(\alpha_{1}+\alpha_{2} \times\right.$ year $)+\left(\beta_{1}+\beta_{2} \times\right.$ year $)$, where $\eta$ is the price elasticity of demand; $p$ is predicted from the logistic equation and equals $1 /\left[1+\mathrm{e}^{(-x x)}\right] ; \alpha_{1}$ and $\alpha_{2}$ are the logit coefficients for $\log \left(\right.$ price) and $\log$ (price) $\times$ year, respectively; and $\beta_{1}$ and $\beta_{2}$ are the conditional coefficients for $\log ($ price $)$ and $\log$ (price) $\times$ year.

${ }^{1}$ Based on a series of power calculations, a $25 \%$ sample was determined to be more than adequate for detecting small price and regulation effects.

${ }^{12}$ While it might be interesting to include a dummy variable indicating whether an individual was a high school dropout, the available data were insufficient to construct such a variable.
} 
indicating the level of education attained by the head of each teenager's household was entered in the models. Because the probability of smoking is negatively correlated with education, these variables serve as a proxy for parental smoking habits, which are known to affect teenage smoking behavior [Hirschman et al. (1984), Syme and Alcalay (1982)].

Several other variables used to model adult cigarette demand were not used in the analysis of teenage smoking, including: (1) birth cohort, due to the narrow time span of the teenage data (1976-1980), and (2) price-year and income-year interactions, again due to the narrow time span. We included in the teenage equations an indicator variable for the presence of a law in each respondent's state of residence that restricted the sale or distribution of cigarettes to minors.

\subsection{The 'border problem'}

Informal bootlegging of cigarettes may occur in instances where a particular area borders on another that has lower-priced cigarettes. Even where the difference in cigarette prices between neighboring areas is small, smokers have an incentive to purchase cigarettes in the lower-priced area if they happen to be in that area for some other reason (work, recreation, etc.). Consequently, separate models were estimated using (1) all of the cases, and (2) only those cases that did not border on an area with lower cigarette prices. ${ }^{13}$ Because including the border cases in the analysis adds systematic measurement error into the price variable, which in turn biases the estimated coefficients, we report only the non-border results for adults. ${ }^{14}$

In the case of teenagers, however, the decision as to which set of results is appropriate (i.e., those estimated using all of the cases or just the non-border ones) is less clear, as arguments can be made either way. To be sure, teenagers must engage in at least some amount of bootlegging, because in many places they are able to drive beginning at age 16 . On the other hand, because the NHANES II data include teenagers between the ages of 12 and 17 , roughly two-thirds of the teenage respondents are unable to drive (although some may have older friends who can). Additionally, teenagers may have fewer opportunities to purchase cigarettes in lower-priced areas.

Rather than attempt to resolve this issue on theoretical grounds, we estimated the teenage generalized linear model with and without border cases. We found that the coefficients included in the model were insensitive

\footnotetext{
${ }^{13} \mathrm{~A}$ Wald test was performed to test for differences between a generalized linear model estimated with just 'border' cases and one that included only 'non-border' cases. The test revealed that the estimated parameters were significantly different $(p<0.025)$.

${ }^{14}$ Approximately one-third of the respondents lived in border areas. Given the large number of cases available for analysis, omitting the border people did not appreciably affect the precision of the estimates.
} 
to the inclusion of border cases. However, we were able to obtain more precise estimates by including the border cases, as doing so increased the sample size by approximately $50 \%$. Consequently, the teenage results reported below are based on all of the available observations on teenagers.

\section{Results}

\subsection{Adult demand for cigarettes}

Table 1 contains the results for four different specifications of the generalized linear (Poisson-like) model. The four equations differ as follows:

- Eq. (1), which is the 'base' model, contains variables for price, regulation, income, and year (coded as 70,74, 76, etc.).

- Eq. (2) adds variables for age and sex to the variables included in eq. (1).

- Eq. (3) adds a group of variables measuring cohort effects to the same set of variables as eq. (2).

- Eq. (4) is the full cigarette demand model.

The model's coefficients can be interpreted as representing the overall effects of each covariate on smoking behavior. That is, because both the 'zeros' (i.e., never- and former-smokers) and current smokers were used to estimate the equations, the coefficients account for the effects of the variables on both the decision to smoke and, given that one decides to smoke, the number of packs smoked per day.

The main parameters of interest (i.e., price and regulation) are somewhat sensitive to the equation's specification. For example, the magnitude of the price coefficient more than doubles going from the base model to the full model. The coefficients for most of the remaining variables, however, appear to be relatively stable across equations.

Several other findings are noteworthy. First, there are statistically significant price-year and income-year interactions, indicating that the price and income elasticities of demand are changing over time. ${ }^{15}$ Second, the regulation index has a consistently strong negative influence on the number of packs smoked - more stringent regulation significantly reduces cigarette consumption. Third, taken together, the education and education-year interaction variables exhibit the expected pattern - that is, cigarette consumption declines as education increases. Fourth, cohort effects appear to be important (particularly with respect to males), as evidenced by the coefficients and $t$ statistics for the cohort and male-cohort interaction variables. ${ }^{16}$ Fifth, other

\footnotetext{
${ }^{15}$ Other studies [e.g., Laughhunn and Lyon (1971)] found no such interaction effects, and, consequently, concluded that the demand for cigarettes was stable.

${ }^{16}$ An $F$-test indicated that the cohort and male-cohort variables were significant at the 0.001 level.
} 
Table I

Estimated generalized linear model regression equations for packs per day (adults) ( $t$-statistics in parentheses).*

\begin{tabular}{|c|c|c|c|c|}
\hline & (1) & (2) & (3) & (4) \\
\hline Intercept & $\begin{array}{c}-2.777 \\
(-1.103)\end{array}$ & $\begin{array}{c}-7.740 \\
(-3.169)\end{array}$ & $\begin{array}{c}-8.157 \\
(-3.334)\end{array}$ & $\begin{array}{c}-6.806 \\
(-2.768)\end{array}$ \\
\hline $\log$ (price) & $\begin{array}{c}0.485 \\
(0.651)\end{array}$ & $\begin{array}{c}1.244 \\
(1.724)\end{array}$ & $\begin{array}{c}1.317 \\
(1.824)\end{array}$ & $\begin{array}{l}1.389 \\
(1.934)\end{array}$ \\
\hline Year & $\begin{array}{c}0.029 \\
(0.852)\end{array}$ & $\begin{array}{c}0.064 \\
(1.983)\end{array}$ & $\begin{array}{c}0.073 \\
(2.236)\end{array}$ & $\begin{array}{c}0.050 \\
(1.529)\end{array}$ \\
\hline $\log ($ price $) \times$ year & $\begin{array}{c}-0.008 \\
(-0.820)\end{array}$ & $\begin{array}{c}-0.017 \\
(-1.811)\end{array}$ & $\begin{array}{c}-0.018 \\
(-1.914)\end{array}$ & $\begin{array}{c}-0.019 \\
(-1.984)\end{array}$ \\
\hline Income $\times$ year & $\begin{array}{l}-0.0009 \\
(-5.686)\end{array}$ & $\begin{array}{c}-0.001 \\
(-8.228)\end{array}$ & $\begin{array}{c}-0.001 \\
(-8.085)\end{array}$ & $\begin{array}{l}-0.0006 \\
(-3.406)\end{array}$ \\
\hline Regulation index & $\begin{array}{l}-0.111 \\
(-3.988)\end{array}$ & $\begin{array}{l}-0.113 \\
(-4.159)\end{array}$ & $\begin{array}{l}-0.109 \\
(-4.017)\end{array}$ & $\begin{array}{c}-0.081 \\
(-2.997)\end{array}$ \\
\hline Family size & & & & $\begin{array}{c}0.034 \\
(2.526)\end{array}$ \\
\hline Log(Family size) & & & & $\begin{array}{l}-0.287 \\
(-5.256)\end{array}$ \\
\hline Income & $\begin{array}{c}0.069 \\
(5.852)\end{array}$ & $\begin{array}{c}0.089 \\
(7.406)\end{array}$ & $\begin{array}{c}0.088 \\
(7.272)\end{array}$ & $\begin{array}{c}0.047 \\
(3.639)\end{array}$ \\
\hline Less than High School & & & & $\begin{array}{l}-1.548 \\
(-5.009)\end{array}$ \\
\hline High School & & & & $\begin{array}{l}-0.962 \\
(-3.249)\end{array}$ \\
\hline Some College & & & & $\begin{array}{c}-0.638 \\
(-1.912)\end{array}$ \\
\hline Less than High School $\times$ year & & & & $\begin{array}{c}0.032 \\
(7.788)\end{array}$ \\
\hline High School $\times$ year & & & & $\begin{array}{c}0.021 \\
(5.435)\end{array}$ \\
\hline Some College $\times$ year & & & & $\begin{array}{c}0.014 \\
(3.323)\end{array}$ \\
\hline Male & & $\begin{array}{c}0.400 \\
(4.206)\end{array}$ & $\begin{array}{c}0.249 \\
(1.929)\end{array}$ & $\begin{array}{c}0.305 \\
(2.357)\end{array}$ \\
\hline Age & & $\begin{array}{c}0.114 \\
(31.428)\end{array}$ & $\begin{array}{c}0.107 \\
(18.719)\end{array}$ & $\begin{array}{c}0.103 \\
(17.624)\end{array}$ \\
\hline Age $^{2}$ & & $\begin{array}{c}-0.001 \\
(-33.869)\end{array}$ & $\begin{array}{c}-0.001 \\
(-21.747)\end{array}$ & $\begin{array}{c}-0.001 \\
(-21.510)\end{array}$ \\
\hline 1900 Birth cohort & & & $\begin{array}{c}-0.133 \\
(-0.930)\end{array}$ & $\begin{array}{c}-0.134 \\
(-0.940)\end{array}$ \\
\hline 1910 Birth cohort & & & $\begin{array}{c}-0.029 \\
(-0.253)\end{array}$ & $\begin{array}{l}-0.060 \\
(-0.524)\end{array}$ \\
\hline 1920 Birth cohort & & & $\begin{array}{l}-0.029 \\
(-0.301)\end{array}$ & $\begin{array}{l}-0.072 \\
(-0.754)\end{array}$ \\
\hline 1930 Birth cohort & & & $\begin{array}{l}-0.051 \\
(-0.648)\end{array}$ & $\begin{array}{c}-0.099 \\
(-1.258)\end{array}$ \\
\hline 1940 Birth cohort & & & $\begin{array}{c}-0.043 \\
(-0.700)\end{array}$ & $\begin{array}{l}-0.080 \\
(-1.314)\end{array}$ \\
\hline 1950 Birth cohort & & & $\begin{array}{c}-0.141 \\
(-2.780)\end{array}$ & $\begin{array}{l}-0.158 \\
(-3.129)\end{array}$ \\
\hline Male $\times$ age & & $\begin{array}{c}-0.005 \\
(-1.171)\end{array}$ & $\begin{array}{c}-0.014 \\
(-2.043)\end{array}$ & $\begin{array}{c}-0.015 \\
(-2.100)\end{array}$ \\
\hline Male $\times$ age $^{2}$ & & $\begin{array}{c}0.001 \\
(2.741)\end{array}$ & $\begin{array}{r}0.0001 \\
(2.152)\end{array}$ & $\begin{array}{l}0.0002 \\
(2.274)\end{array}$ \\
\hline
\end{tabular}


Table 1 (continued)

\begin{tabular}{|c|c|c|c|c|}
\hline & (1) & (2) & (3) & (4) \\
\hline 1900 Birth cohort $\times$ male & & & $\begin{array}{c}0.717 \\
(5.457)\end{array}$ & $\begin{array}{c}0.668 \\
(5.117)\end{array}$ \\
\hline 1910 Birth cohort $\times$ male & & & $\begin{array}{c}0.580 \\
(5.492)\end{array}$ & $\begin{array}{c}0.542 \\
(5.152)\end{array}$ \\
\hline 1920 Birth cohort $\times$ male & & & $\begin{array}{c}0.513 \\
(5.461)\end{array}$ & $\begin{array}{c}0.507 \\
(5.425)\end{array}$ \\
\hline 1930 Birth cohort $\times$ male & & & $\begin{array}{c}0.448 \\
(5.259)\end{array}$ & $\begin{array}{c}0.465 \\
(5.487)\end{array}$ \\
\hline 1940 Birth cohort $\times$ male & & & $\begin{array}{c}0.447 \\
(5.962)\end{array}$ & $\begin{array}{c}0.462 \\
(6.211)\end{array}$ \\
\hline 1950 Birth cohort $\times$ male & & & $\begin{array}{c}0.344 \\
(4.778)\end{array}$ & $\begin{array}{c}0.363 \\
(5.076)\end{array}$ \\
\hline Non-white & & & & $\begin{array}{c}-0.409 \\
(-18.872)\end{array}$ \\
\hline Widowed & & & & $\begin{array}{c}0.168 \\
(4.184)\end{array}$ \\
\hline Never married & & & & $\begin{array}{r}-0.298 \\
(-12.372)\end{array}$ \\
\hline Divorced & & & & $\begin{array}{c}0.360 \\
(13.258)\end{array}$ \\
\hline Separated & & & & $\begin{array}{c}0.449 \\
(12.005)\end{array}$ \\
\hline
\end{tabular}

Sample size $=84,301$.

factors equal, whites smoke more than non-whites. Finally, with the exception of the people who were never married (which includes young people who may yet start to smoke), married people smoke less than those who are not married.

\subsection{Price and income elasticities of demand}

Because there are significant price-year and income-year interactions, one must compute price and income elasticities on a year-by-year basis. In the case of price elasticities, this can be accomplished using the following formula:

$$
\eta=\beta_{1}+\beta_{2} \times \text { year, }
$$

where $\eta$ is the price elasticity of demand, $\beta_{1}$ is the $\log$ (price) coefficient, and $\beta_{2}$ is the $\log$ (price) $\times$ year coefficient. The income elasticity can be computed as follows:

$$
\varepsilon=\left(\beta_{3}+\beta_{4} \times \text { year }\right) \times \text { income }
$$


Table 2

Estimated price and income elasticities of demand generalized linear model (adults) (standard errors in parentheses).

\begin{tabular}{lcc}
\hline Year & Price elasticity $^{\mathbf{a}}$ & Income elasticity $^{\mathrm{a}}$ \\
\hline 1970 & 0.059 & 0.051 \\
& $(0.076)$ & $(0.015)$ \\
1974 & -0.017 & 0.031 \\
& $(0.062)$ & $(0.014)$ \\
1976 & -0.055 & 0.021 \\
& $(0.063)$ & $(0.015)$ \\
1979 & -0.112 & 0.007 \\
& $(0.075)$ & $(0.016)$ \\
1980 & -0.131 & 0.002 \\
& $(0.081)$ & $(0.017)$ \\
1983 & -0.188 & -0.013 \\
& $(0.102)$ & $(0.020)$ \\
1985 & -0.226 & -0.023 \\
& $(0.118)$ & $(0.022)$ \\
$1988^{\mathrm{b}}$ & -0.283 & -0.038 \\
& $(0.143)$ & $(0.025)$ \\
\hline
\end{tabular}

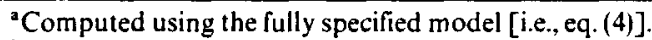

'Extrapolated.

where $\varepsilon$ is the income elasticity of demand, $\beta_{3}$ is the income coefficient, $\beta_{4}$ is the income $\times$ year coefficient, and income is average family income.

Price and income elasticities of demand, calculated using eq. (4) in table 1 , for each of the years included in the data set as well as for 1988 are shown in table 2. The predictions for 1988 are extrapolations beyond the range of the data and, as such, may not be valid indications of current elasticities.

Although the price elasticity has become increasingly negative over time, the estimated price elasticities are low in comparison to previous estimates. ${ }^{17}$ Using the 1985 estimate, if the price of cigarettes were increased by $10 \%$, overall per capita smoking would decrease by $2.3 \%$, or roughly a fifth of a cigarette per day if we allow for underreporting. ${ }^{18}$

The estimated income elasticities change from positive to negative over time, indicating that cigarettes may now be an inferior good. However, with the exceptions of 1970 and 1974 , the estimated elasticities are not statistically

\footnotetext{
${ }^{17}$ For the most part, the estimated price elasticities for adjacent years are not statistically different from each other. However, there is a statistically significant difference between 1970 (or 1974) and 1985.

${ }^{18}$ These calculations are based on a population that includes smokers and non-smokers, because the data used to estimate the model included people with zero and positive consumption. Thus, the estimated decreases in consumption, which are presented in terms of cigarettes, can result from a decrease in the smoking participation rate and/or a reduction in the number of cigarettes smoked per smoker. The mean number of reported packs smoked per day was 0.34 .
} 
different from zero. These estimates are low in comparison to estimates reported in the literature, which is probably attributable to the more recent data that were used in this study - data that reflect the changing demographics of cigarette smokers (i.e., a disproportionate number of poor, and poorly educated, people are now smokers). ${ }^{19.20}$

\subsection{Effect of regulations on cigarette demand}

The other policy variable of interest is the regulation index. This index had a depressing effect on cigarette consumption across all specifications in table 1 , and the magnitude of the effect was robust to the set of covariates included in the equation. The percentage change in packs smoked due to an increase in the regulation index can be computed using the estimated coefficient from the full model [table 1, eq. (4)] as follows:

$$
\text { Percent change in packs smoked }=\left[e^{-0.081 x}-1\right] \times 100 \text {, }
$$

where $x$ is a regulation index value. If legislators passed a law that would increase the index from 0.25 to 1 - for example by increasing the stringency of the laws in place from restricting smoking in a handful of minor places (e.g., waiting rooms, libraries, etc.) to restricting smoking at private worksites - then overall per capita smoking would decrease by $5.9 \% \%^{21,22}$ To achieve the same percentage reduction through a tax-induced price increase, the current price of cigarettes would have to increase by approximately $31 \%^{{ }^{23}}$

\subsection{Teenage demand for cigarettes}

Table 3 shows the results from the generalized linear model for teenagers.

\footnotetext{
${ }^{19}$ Our modeling approach did not enable us to distinguish educated people who never smoked from quitters. Because well-educated people have been more likely to quit in comparison to poorly-educated people, part of the observed income and education effects may be attributable to this phenomenon.

${ }^{20}$ The NHIS data set identifies each family's income category (e.g., $\$ 15,000-\$ 19,999$ ). As a result, attempts such as ours to impute an income value for each category (e.g., $\$ 17,547$ ) will measure a family's true income with error. The effect of these errors in the variables will be to bias our estimated income elasticities toward zero.

${ }^{21}$ We cannot dismiss the possibility that the regulation effect is endogenous or reflects the omitted variable bias due to the effect of public sentiment against smoking on the propensity to start smoking. However, it is likely that the within-state variance associated with smoking is considerably greater than the between-state taste for cigarettes variance, the latter of which may influence the stringency of the regulations. We address this issue further in the discussion section.

${ }^{22}$ At the suggestion of a reviewer, we tested for a regulation index-year interaction and found that it reduced the price and price-year interaction variables to insignificance. However, the inclusion of the regulation-year interaction introduced substantial multicollinearity into the equation.

${ }^{23}$ Calculated using the 1985 estimated elasticity of -0.23 .
} 
Table 3

Estimated generalized linear model coefficients for packs per day (teenagers). ${ }^{3}$

\begin{tabular}{lrr}
\hline Variable & Coefficient & $t$-Statistic \\
\hline Intercept & -8.583 & -1.655 \\
Log(price) & 0.859 & 1.448 \\
Year & -0.038 & -0.696 \\
Family size & 0.065 & 0.612 \\
Log(Family size) & -0.537 & -1.101 \\
Income & -0.051 & -3.438 \\
Household head education < High School & 0.970 & 2.475 \\
Household head education, High School & 0.783 & 2.010 \\
Household head education, Some College & 0.707 & 1.759 \\
Male & -0.034 & -0.277 \\
Age & 0.435 & 9.923 \\
Non-white & -1.402 & -5.521 \\
Regulation index & -0.701 & -2.104 \\
Prohibits sale to minors & 0.141 & 0.703 \\
\hline
\end{tabular}

aSample size $=1,891$.

Price has a statistically insignificant effect on consumption and is of the 'wrong' sign (i.e., price is positively related to consumption). ${ }^{24}$ Given the coefficient's standard error of 0.59 (not shown) and a $95 \%$ confidence interval ranging between -0.30 and 2.02 , we cannot reject the hypothesis that the teenage price elasticity of demand is statistically different from the adult estimate of -0.23 for 1985 . However, the teenage price elasticity estimate differs significantly from Lewit et al.'s (1981) teenage price elasticity estimates of -1.19 for the decision to smoke and -1.44 for the quantity smoked.

In contrast to price changes, anti-smoking regulations appear to have a strong negative and statistically significant $(p<0.05)$ effect on consumption. Specifically, if the regulation index were increased from 0.25 to 1 , teenage consumption would decline by $41 \%{ }^{25}$ However, once we control for other regulations, the dummy variable indicating whether there is a law or regulation in effect in the respondent's state governing the sale of cigarettes to minors is statistically insignificant.

Teenage cigarette consumption is negatively related to both family income and parental education. Because these variables are also negatively related to

\footnotetext{
${ }^{24}$ In the absence of any interaction terms involving the price variable, the price coefficient can be interpreted directly as the elasticity of demand.

${ }^{25}$ The regulation index is most effective in preventing teens from starting to smoke, rather than in encouraging current teenage smokers to curtail their consumption (results not shown). It should be noted that although the regulation index value of 1 signifies that a regulation is in place that restricts smoking in private worksites, states that regulate smoking in private worksites also typically regulate smoking in a variety of other public places, including places frequented by teenagers (e.g., schools, libraries, and sports arenas).
} 
Table 4

Estimated price elasticities of demand - two-part
model (adults).

Table 5

Selected two-part model coefficients ( $t$-statistics in parentheses).

\begin{tabular}{lcc}
\hline Variable & $\begin{array}{c}\text { Probability } \\
\text { of smoking }\end{array}$ & $\begin{array}{c}\text { Level of smoking } \\
\text { by current smokers }\end{array}$ \\
\hline Log(price) & 1.691 & 0.503 \\
& $(1.78)$ & $(1.22)$ \\
Year & 0.054 & 0.027 \\
& $(1.25)$ & $(1.46)$ \\
Log(price) $\times$ year & -0.023 & -0.007 \\
& $(-1.80)$ & $(-1.23)$ \\
Income & 0.066 & 0.010 \\
Income $\times$ year & $(3.91)$ & $(1.26)$ \\
& -0.0009 & -0.0001 \\
Regulation index & $(-3.95)$ & $(-0.79)$ \\
& -0.045 & -0.048 \\
& $(-1.28)$ & $(-3.10)$
\end{tabular}

parental smoking behavior, they may serve as proxies for parental behavior in the teenage demand models. Hence, the increased propensity to smoke by children of poorly educated adults may not be due to the fact that their parents were poorly educated, but rather because their parents were more likely to smoke.

\subsection{Two-part model results}

Although the generalized linear model provides estimates of overall price and regulation effects, the two-part model shows where in the smoking process each of the determinants of the demand for cigarettes exerts its greater influence. The two-part model also serves to check the robustness of the results from the generalized linear model.

Tables 4 and 5 show estimated price elasticities and selected coefficients 
from the two-part model, respectively. ${ }^{26}$ Table 4 indicates that price changes have their greatest effect on the decision to become a smoker rather than on the number of cigarettes smoked, given that one has chosen to smoke. Additionally, the total price elasticity estimates from the two-part model are very close to the generalized linear model estimates. Thus, the price elasticity estimates appear insensitive to the statistical method used to model cigarette demand.

The regulation index only had a statistically significant effect on the number of cigarettes smoked, not the decision to be a current smoker. Hence, for relatively mature smokers, regulations restricting smoking in public places may reduce consumption simply by limiting opportunities to smoke.

We also used the two-part model to examine the effects of prices and regulations on teenage smoking. Price did not have a statistically significant effect in either of the model's parts. The regulation index exerted a statistically significant influence in the logit for the probability of being a smoker but not in the conditional equation. This is the precise opposite of the adult two-part model results, where the regulation index was only statistically significant in the conditional equation. Because more of the variance in cigarettes smoked among teenagers is in the decision to smoke, this result is not surprising. In sum, although laws and regulations restricting smoking in public places may not affect adults' decisions to continue to smoke, but merely the number of cigarettes smoked, regulations appear to have an important influence on teenagers' decisions to start smoking.

\section{Discussion}

Our analysis of adult cigarette demand suggests that the price elasticity of demand is low. Moreover, the structure of the demand for cigarettes is changing over time, as the statistically significant price-year and income-year interactions indicate. The point estimates of the price elasticity have gone from 0.06 in 1970 to -0.23 in 1985 . These estimates are low in comparison to earlier studies. However, it should be noted that the $95 \%$ confidence interval for the 1985 estimate spans -0.46 to 0.005 , a range that encompasses several of the earlier estimates [e.g., Lewit and Coate (1982), Warner (1981), Witt and Pass (1983), Young (1983)]. Nevertheless, people may be less responsive to cigarette price changes than previously thought. Additionally, we found that regulations restricting smoking in public places have a significant negative effect on cigarette demand.

The teenage smoking results suggest that teenagers may not be as

\footnotetext{
${ }^{26}$ The complete results of the two-part model are reported in Wasserman (1988).
} 
responsive to price changes as previous studies found. However, regulations restricting smoking in public places appear to have a considerable impact on teenage smoking behavior. In contrast to adults, regulations affect the teenager's decision to become a smoker rather than the number of cigarettes smoked, given that he or she becomes a smoker.

\subsection{Comparisons with the literature}

To better understand why our results diverge from those reported in the literature, we used 1976 NHIS data and attempted to replicate the demand equations estimated by Lewit and Coate (1982) for adults. We obtained coefficients that were strikingly similar, indicating that major errors in data entry and/or coding could be ruled out as a source of discrepancies in the results of the two studies. However, when we added the regulation index to the Lewit and Coate specification, we found that the price coefficients for the three equations they estimated (i.e., number of cigarettes smoked by smokers and non-smokers, using zero for non-smokers; smoking participation; and number of cigarettes smoked by smokers) dropped dramatically. Thus, a substantial portion of the difference between our price elasticity estimates and the higher estimates found in other studies can in all likelihood be attributed to our inclusion of the regulation index. Given the positive correlation between prices and regulations, the earlier studies' results may be biased upward due to the omission of regulations from their models.

Although the regulation index variable appears important, some might argue that it is properly considered endogenous, whereas we have treated it as exogenous. Moreover, the price variable could perhaps also be considered endogenous. We agree that if the state or locality were the unit of observation, regulations and prices may well be endogenous. In our work, however, the individual is the unit of observation, so any simultaneous equations bias should be nil for either price or regulation. Put another way, any individual's decision to smoke will negligibly influence the willingness of legislators to enact laws restricting smoking in public places or raise cigarette taxes.

A more plausible model might hold that public sentiment against smoking produces higher taxes, more stringent regulations, peer pressure to refrain from smoking, and so on. However, because public sentiment is difficult to measure, it has been excluded from virtually all data sets that have been used to model cigarette demand. Consequently, all correlated but included variables will suffer from an omitted variable bias, with the omission of a public sentiment variable biasing both the price and regulation index coefficients away from zero. One could even argue that the failure to include a direct measure of public sentiment is an indictment of all micro studies of cigarette demand published to date. But in defense of our own study, if public 
sentiment is important, the inclusion of a proxy (i.e., the regulation index) should reduce the omitted variable bias in the estimated price coefficient.

\subsection{Policy implications}

In assessing the policy implications of these results, it is important to recognize that developing effective and economically efficient policies to discourage smoking is inherently difficult. The fact that there are over 50 million smokers, that there are strong addictive aspects of smoking, and that much remains to be learned about the costs and benefits of alternative smoking reduction strategies mean that we are still some time away from transforming our society into a smoke-free one. Needless to say, virtually all proposals for reducing smoking have been fraught with controversy, as they may impinge on individuals' rights (both smokers' and non-smokers'), and/or threaten the financial well-being of firms connected with the production and distribution of cigarettes and other tobacco products.

Perhaps the largest problem associated with using cigarette excise taxes to reduce consumption is determining the appropriate level of taxation. As this and other analyses suggest, people are at least somewhat responsive to cigarette price changes (i.e., the elasticity of demand is not zero). The relatively inelastic demand for cigarettes suggests that it may take moderate to large cigarette taxes to reduce smoking substantially. Nevertheless, these results do not, in and of themselves, guide us to the precise level at which the tax should be set, and different rationales for levying taxes necessarily imply different tax levels [Manning et al. (1989)].

A second difficulty associated with cigarette excise taxes concerns the distributional consequences of higher taxes. As we have seen, cigarette smoking is increasingly becoming a phenomenon associated with the poor and less-educated people in our society. Moreover, given the absence of a price-income interaction effect, it appears that the poor are no more responsive to price changes than the wealthy. Thus, in light of these elasticity estimates, higher prices will simply lead to increased expenditures on cigarettes while achieving only moderate decreases in consumption. The fraction of a poor smoker's income that is spent on cigarettes will increase vis-à-vis that of the wealthy smoker. On the other hand, because tobacco tax revenues only account for a small fraction of all federal and state tax revenues, relatively small changes in the income tax structure could be used to compensate for the effect of higher cigarette taxes on the distribution of income. Whether this type of compensation would be politically feasible is uncertain.

The case for discouraging smoking through regulation is also less than clear-cut. For example, there are important property rights issues at stake i.e., the right of non-smokers to a smoke-free environment vs. the right of 
smokers to smoke wherever and whenever they want. ${ }^{27}$ Additionally, despite the significant negative effect of the regulation index used in both the adult and teenage demand models, we cannot dismiss the possibility that a particular state's regulations may reflect its population's anti-smoking attitudes and not cause lower consumption. However, as already discussed, the use of micro data to estimate cigarette demand militates against this possibility.

In addition to reducing opportunities to smoke, stringent regulations are bound to convey to the smoker that his or her behavior is in some sense socially unacceptable, and most of us are at least somewhat susceptible to messages we receive regarding the social desirability of our actions. Interestingly, the regulation index has its strongest impact on teenagers, who may be even more sensitive to how others view their behavior than adults. A final benefit associated with the regulatory approach is that it concomitantly offers non-smokers protection against passive smoking while frequenting those places where smoking is either restricted or prohibited.

\footnotetext{
${ }^{27}$ From an economic perspective, government action to resolve these property rights is warranted due to the high transaction costs that would be incurred if dispute resolution in this area were to assume a market orientation.
}

\section{References}

Baltagi, B.H. and D. Levin, 1986, Estimating dynamic demand for cigarettes using panel data: The effects of bootlegging, taxation and advertising reconsidered, Review of Economics and Statistics 68, 148-155.

Becker, G.S., M. Grossman and K.M. Murphy, 1990, An empirical analysis of cigarette addiction, National Bureau of Economic Research Working paper no. 3322 (National Bureau of Economic Research, Cambridge, MA).

Centers for Disease Control, 1987, Smoking-attributable mortality and years of potential life lost - United States, 1984, Morbidity and Mortality Weekly Report 36, 693-697.

Chaloupka, F.J., 1988, An economic analysis of addictive behavior: The case of cigarette smoking, Unpublished manuscript.

Chaloupka, F.J., 1990, Rational addictive behavior and cigarette smoking, National Bureau of Economic Research Working paper no. 3268 (National Bureau of Economic Research, Cambridge, MA).

Cragg, J.G., 1971, Some statistical models for limited dependent variables with applications to the demand for durable goods, Econometrica 39, 829-844.

Fujii, E.T., 1980, The demand for cigarettes: Further empirical evidence and its implications for public policy, Applied Economics 12, 479-489.

Harris, J.E., 1983, Cigarette smoking among successive birth cohorts of men and women in the United States during 1900-80, Journal of the National Cancer Institute 71, 473-479.

Hatziandreu, E.J., J.P. Pierce, M.C. Fiore et al., 1989, The reliability of self-reported cigarette consumption in the United States, American Journal of Public Health 79, 1020-1023.

Hirschman, R.S., H. Leventhal and K. Glynn, 1984, The development of smoking behavior: Conceptualization and supportive cross-sectional survey data, Journal of Applied Social Psychology 14, 184-206.

Laughhunn, D.J. and H.L. Lyon, 1971, The feasibility of tax induced price increases as a deterrent to cigarette consumption, Journal of Business Administration 3, 27-35.

Lewit, E.M. and D. Coate, 1982, The potential for using excise taxes to reduce smoking, Journal of Health Economics 1, 121-145. 
Lewit, E.M., D. Coate and M. Grossman, 1981, The effects of government regulation on teenage smoking, Journal of Law and Economics 24, 545-570.

Manning. W.G., E.B. Keeler, J.P. Newhouse, E.M. Sloss and J. Wasserman, 1989, The taxes of sin: Do smokers and drinkers pay their way?, Journal of the American Medical Association $261,1604-1609$.

Marquis, K.H., N. Duan, M.S. Marquis and J.M. Polich, 1981, Response errors in sensitive survey topics: Estimates, effects, and correction options, R-2710/2-HHS (The RAND Corporation, Santa Monica, CA).

McCullagh, P. and J.A. Nelder, 1983, Generalized linear models (Chapman \& Hall, London).

Mullahy, J., 1985, Cigarette smoking: Habits, health concerns, and heterogeneous unobservables in a microeconomic analysis of consumer demand, Ph.D. Dissertation (University of Virginia, VA).

Nelder, J.A. and R.W.M. Wedderburn, 1973, Generalized linear models, Journal of the Royal Statistical Society A 135, 370-384.

Schoenborn, C.A., 1987, Findings from the National Health Interview Survey, Evaluation and the Health Professions 10, 438-459.

Syme, S.L. and R. Alcalay, 1982, Control of cigarette smoking from a social perspective, Annual Review of Public Health, 179-199.

Tobacco Institute, 1986, The tax burden on tobacco 21 (Tobacco Institute, Washington, DC).

U.S. Department of Health and Human Services, 1989, Reducing the health consequences of smoking: 25 years of progress, A Report of the Surgeon General (U.S. Department of Health and Human Services, Rockville, MD).

U.S. Department of Health and Human Services, 1986a, The health consequences of involuntary smoking, A Report of the Surgeon General (U.S. Department of Health and Human Services, Rockville, MD).

U.S. Department of Health and Human Services, 1986b, Smoking and health: A national status report (U.S. Department of Health and Human Services, Rockville, MD).

U.S. Department of Health and Human Services, 1982, The health consequences of smoking: Cancer, A Report of the Surgeon General (U.S. Department of Health and Human Services, Rockville, MD).

Warner, K.E., 1981, Cigarette smoking in the 1970's: The impact of the antismoking campaigns on consumption, Science 211, 729-731.

Warner, K.E., 1978, Possible increases in the underreporting of cigarette consumption, Journal of the American Statistical Association 73, 314-317.

Wasserman, J., 1988, Excise taxes, regulation, and the demand for cigarettes, Report P-7498RGS (The RAND Corporation, Santa Monica, CA).

Witt, S.F. and C.L. Pass, 1983, Forecasting cigarette consumption: The causal model approach, International Journal of Social Economics 10, 18-33.

Young, T., 1983, The demand for cigarettes: Alternative specifications of Fujii's model, Applied Economics 15, 203-211. 